\title{
Emergency bilateral internal iliac artery ligation in massive obstetric haemorrhage: 5 years experience At Tertiary Care Hospital.
}

\footnotetext{
1. FCPS

Associate Professor Gynaecology \&

Obstetrics

Faisalabad Medical University,

Faisalabad.

2. FCPS

Professor Gynaecology \& Obstetrics

Faisalabad Medical University,

Faisalabad.

3. FCPS

Associate Professor Gynaecology \& Obstetrics

Faisalabad Medical University,

Faisalabad.

4. FCPS

Professor Gynaecology \& Obstetrics Faisalabad Medical University,

Faisalabad.

Correspondence Address:

Dr. Saadia Saleem

Department of Gynaecology \&

Obstetrics

Faisalabad Medical University,

Faisalabad.

zahidakramahf@gmail.com
}

Article received on:

25/11/2019

Accepted for publication:

$18 / 05 / 2020$

\section{Saadia Saleem ${ }^{1}$, Tasnim Tahira ${ }^{2}$, Naureen Javed ${ }^{3}$, Sumera Tahir ${ }^{4}$}

ABSTRACT... Objectives: To study the efficacy and safety of emergency bilateral internal iliac artery ligation (BIAL) in arresting massive obstetric haemorrahge. Study Design: Retrospective study. Setting: Department of Obstetrics and Gynaecology Unit-I, Allied Hospital, Faisalabad. Period: January 2014 to December 2018. Material \& Methods: Fifty eight (58) patients with obstetric haemorrhage were included in this retrospective study. Bilateral internal iliac artery ligation was performed to control massive postpartum haemorrhage, post-operative internal haemorrhage. Results: The fifty eight (58) women underwent BIAl. Booked cases were onlhy $(27 \%)$ and $(73 \%)$ were unbooked. Out of 58 women $16(27 \%)$ women were with morbid adherent placenta, $14(24 \%)$ with uterine atony, $11(19 \%)$ uterine rupture, $9(17 \%)$ post-operative internal haemorrhage and $8(13 \%)$ coagulopathy were underwent BIAL. Out of 58 women $15(36 \%)$ ended in hysterectomy because of failure to control bleeding and uterus preserved in (64\%). Overall efficacy in term of saving maternal life was $90 \%$. One women had ureteric injury that was managed by Urologist. One another patient required re-laparotomy for persistant internal haemorrahge. Conclusion: Bilateral internal iliac artery ligation is safe and effective technique to control massive obstetric haemorrhage. Timely decision is also important to prevent hysterectomy. BIAL should include in algorithm to control intractable obstetric haemorrhage and consultant obstetricians and gynaecologist should learn that technique.

Key words: Internal lliac Artery Ligation, Obstetric Haemorrhage, Saving Maternal Life and Uterus.

\section{INTRODUCTION}

Obstetric haemorrhage is still one of the five leading causes of maternal morbidity and mortality. ${ }^{1}$ Postpartum haemorrhage is main contributing reason. Its prevalence is between $1-5 \%$ of all deliveries. ${ }^{2}$ Massive haemorrhage after child birth occurs in 1-2/1000 deliveries. ${ }^{3,4}$ Approximately 140,000 women are dying each year worldwide. ${ }^{5}$ Overall haemorrhage contributes for $27 \%$ of all maternal deaths. ${ }^{6}$ Some patients with massive obstetric haemorrhae are those who developed internal bleed after obstetrical hysterectomy or caesarean section. Prompt surgical intervention not only save the maternal life but also her uterus. Ligation of internal iliac arteries is recognized as one of the best technique to control profuse obstetric haemorrhage and considered as a life saving procedure. Bilateral internal iliac artery ligation does result in significant decrease (49\%) in blood supply to pelvic organs. ${ }^{7}$ The efficacy of this procedure in avoiding hysterectomy for massive postpartum haemorrhage has been reported in one study is upto $50 \%^{8}$ and will control pelvic haemorrhage in $75 \%$ of cases. ${ }^{9}$ Internal iliac (hypogastric) artery ligation was started by and of $19^{\text {th }}$ century to control massive haemorrhage from uterus with advanced cervical cancer. ${ }^{10}$ Since that time on, it has been a mainstay of controlling intractable obstetric haemorrhage.

Complication of Bilateral Internal lliac artery Ligation (BIAL)s include damage to internal iliac vein and ureter. Tissue edema, ongoing haemorrhage and presence of atonic uterus may be the contributing factors. It may also result in 
accidental ligation of external iliac artery but this is safe procedure in experienced hands. So bilateral inferior hypogastric artery ligation should be taught during obstetric and gynaecologic training, or at least one member of oncall team should be experienced. The present study aimed to share our experience in regarding the usefulness and safety of internal iliac artery ligation in control of massive pelvic haemorrhage.

\section{MATERIAL \& METHODS}

The study was carried out from January 2014 to December 2018 in Gynaecology Unit-I of Allied Hospital, Faisalabad Medical University (FMU), which is a tertiary care centre dealing complicated and high risk case and referrals. The data of all these patients were filled on proforma who underwent internal iliac artery ligation. The demographic characteristics and clinical data including age, parity, gestational age, mode of delivery, reason of postpartum haemorrhage or internal haemorrhage, need of additional surgical procedure, number of blood transfusions and associated morbidity and mortality were recorded.

\section{Surgical Techniques}

The surgical technique for bilateral hypogastric artery ligation is quite easy for gynaecological oncologist and experienced surgeon, as they are familiar with the anatomy of the lateral pelvic wall. In our study all are done by experienced surgeon on call that day, which is decided by consultant obstetrician operating and dealing massive pelvic haemorrhage. The parietal peritoneum picked up and divided at lateral pelvic wall at the level of pelvic brim. Ureter was identified as it crosses the common iliac vessels and reflected medially. The right hypogastric (internal iliac) artery was traced from above downwards until it divides into anterior and posterior divisions. The anterior division is ligated by passing right angle clamp from lateral to medial with double strand absorbable suture (vicryl\# 1) at least $3 \mathrm{~cm}$ distal to bifurcation ${ }^{33}$. The same procedure is repeated on left side internal iliac artery. The femoral pulses were palpated at the completion of BIAL. Efficacy of BIAL was determined in term of controlling bleeding, conservating uterus and saving maternal lives. The intra-operative/post-operative complications, admission to intensive care unit, number of blood transfusions and component therapy were noted. The collected data were entered for statistical analysis.

\section{RESULTS}

In this study period from January 2014 to December 2018, total number of deliveries conducted in gynaecology and obstetrics unit Allied Hospital Faisalabad were sixty one thousand \& four hundred. Fifty eight patients presented with severe postpartum haemorrhage and massive post-operative internal haemorrhage, underwent bilateral internal iliac artery ligation. Referred cases with severe obstetric haemorrhage were sixty five (65\%). Out of fifty eight patient, 16 (27\%) were booked and 42 (73\%) were unbooked and other demographic characteristics were shown in Table-I.

Morbid adherent placenta was the common indication (27\%). Other indication were atonic post-partum haemorrhage (24\%), uterine rupture (19\%), post-operative internal haemorrhage (15\%) and coagulopathy (13\%). Out of 8 women with coagulopathy, 3 had HELLP syndrome, 3 had disseminated intravascular coagulation and 2 had idiopathic thrombocytopenic purpura (ITP). Out of 9 women with post-operative internal haemorrhage 7 were after obstetrical hysterectomy and 2 were after total abdominal hysterectomy (TAH) as shown in Table-Il. These cases were referred to Allied Hospital in very critical condition, later on 6 expired in ICU (10\%). But overall efficacy of bilateral internal iliac artery ligation in term of saving maternal life is $90 \%$ (52 cases).

Out of 58 patients, 41 patients had massive postpartum haemorrhage, with uterine salvage was $64 \%$ by BIAL. 15 (36\%) women ended in hysterectomy because of failure to control bleeding. Additional procedures along with $\mathrm{BIAL}$ are uterine artery ligation, $\beta$ lynch suture, abdominal packs and hysterectomy as mentioned in Table-III. Out of 58 patients, 52 (90\%) were successfully managed by BIAL and discharged between (7-14) days. Mean blood loss, total blood transfusion and blood components, pre- 
operative and post-operative haemoglobin are shown in Table-IV.

Out of 58 patients, 2 had complication of BIAL. One had re-laparotomy for persistent haemorrhage but she expired due to DIC. Other patient had ureteric injury but immediately managed by Urologist.

Overall efficacy of this procedure in term of conservation of uterus was $64 \%$. Highest No. of patients had uterine salvage were due to atonic postpartum haemorrhage (72\%) followed by rupture uterus (64\%) and adherent placenta (56\%) as shown in Table-V and VI.

\begin{tabular}{|l|c|c|}
\hline \multicolumn{1}{|c|}{ Age in years } & $\mathbf{2 1 - 4 2}$ & \%age \\
\hline History of C-section & 43 & $74 \%$ \\
\hline Booked & 16 & $27 \%$ \\
\hline Unbooked & 42 & $73 \%$ \\
\hline Referred cases & 38 & $65 \%$ \\
\hline Vaginal delivery & 15 & $26 \%$ \\
\hline Caesarean section & 43 & $74 \%$ \\
\hline
\end{tabular}

Table-I. Demographic and clinical characteristics

\begin{tabular}{|l|c|c|}
\hline \multicolumn{1}{|c|}{ Indications } & $\begin{array}{c}\text { No. of } \\
\text { Patients }\end{array}$ & \%age \\
\hline Adherent placenta & 16 & $27 \%$ \\
\hline Atonic postpartum haemorrhgae & 14 & $24 \%$ \\
\hline Uterine rupture & 11 & $19 \%$ \\
\hline Post-operative internal haemorrhage & 9 & $17 \%$ \\
\hline Coagulopathy & 8 & $13 \%$ \\
\hline
\end{tabular}

Table-II. Indications of internal iliac artery ligation

\begin{tabular}{|l|c|c|}
\hline \multicolumn{1}{|c|}{ Other procedure } & $\begin{array}{c}\text { No. of } \\
\text { Patients }\end{array}$ & $\%$ age \\
\hline Uterine artery ligation & 27 & $70 \%$ \\
\hline Uterine artery ligation and $\beta$-lynch & 18 & $48 \%$ \\
\hline Obstetric hystrectomy & 15 & $36 \%$ \\
\hline Abdominal packs & 8 & $13 \%$ \\
\hline
\end{tabular}

Table-III. Other additional procedures along with BIAL

\begin{tabular}{|l|c|}
\hline \multicolumn{1}{|c|}{ Parameter } & $\begin{array}{c}\text { Value Mean } \pm \\
\text { SD. }\end{array}$ \\
\hline Mean blood loss $(\mathrm{ml})$ & $2000(1500-3000)$ \\
\hline Pre-op hemoglobin level g/dl & $6.0(4-7)$ \\
\hline Post-op hemoglobin level g/dl & $9.0(7-10)$ \\
\hline Total blood transfusion & $5(10-12)$ \\
\hline Fresh frozen plasm & $4(5-10)$ \\
\hline Platelets & $3(4-6)$ \\
\hline Post operative hospital stay (days) & $(7-10)$ \\
\hline Admission to intensive care unit (days) & $2-6$ \\
\hline
\end{tabular}

Table-IV. Other clinical characteristic

\begin{tabular}{|l|c|c|c|}
\hline \multicolumn{1}{|c|}{ Indications } & Hysterectomy & $\begin{array}{c}\text { Uterus } \\
\text { age }\end{array}$ & conserved \\
\hline Uterine atony & 4 & $28 \%$ & $72 \%$ \\
\hline Rupture uterus & 4 & $36 \%$ & $64 \%$ \\
\hline Adherent placenta & 7 & $44 \%$ & $56 \%$ \\
\hline
\end{tabular}

Table-V. Indications and success of conserving uterus

\begin{tabular}{|c|c|}
\hline Uterus Conserved & Maternal Life Saved \\
\hline $64 \%$ & $90 \%$ \\
\hline
\end{tabular}

Table-VI. Efficacy of procedure

\section{DISCUSSION}

Obstetric haemorrhage is one of the most common causes of maternal morbidity and mortality. Over theyears confidential enquires highlighted a variety of substandard care issues and emphasized on importance of local procedures and policies for rapid and appropriate responses which should be rehearsed so once massive obstetric haemorrhage occurs management should follow sequence of therapeutic options by consultant obstetrician. The recent British committee for standards in haematology $(\mathrm{BCSH})$ guidelines include a useful algorithm for management of major obstetric haemorrhage. Medical measures to control postpartum haemorrhage are uterotonic agents, prostaglandin analogues. When bleeding continues despite drugs, surgical intervention should be considered. The various surgical procedures are uterine artery ligation, B-lynch brace suture, bilateral internal artery ligation and hysterectomy. But choice of procedure depends upon parity, desire for child bearing, degree of shock and expertise of surgeon. Bilateral internal iliac artery ligation is safe and effective procedure and not only save maternal life but also conserve uterus. Many gynaecologist fear that cessation of blood supply may cause damage to pelvic organ but there are several reports of normal ovarian reserve and pregnancies after bilateral ligation of hypogastric arteries. ${ }^{12,23}$

In our study fifty eight patients underwent BIAL. Total number of deliveries conducted in five years study period were sixty one thousand four hundred. Most of the patients who had postpartum haemorrhage was controlled by uterotonic drugs, uterine artery ligation and B-lynch suture only. Post-operative internal haemorrhage was 
also best managed by laparotomy and securing haemostasis over stitch line and pedicles. But out of 1180 patients with obstetric haemorrhage (PPH + internal haemorrhage) (6\%) required bilateral internal artery ligation, which is comparable with study carried out by Yavuz Simsek et al (8.2\%). ${ }^{12}$

In our study, the efficacy of BIAL was found to be $90 \%$ in term saving maternal life. This was comparable to Patil et al $(93 \%)^{13}$, Naithani et al $95 \% .{ }^{14}$ Our study carried out in tertiary care center, and received $65 \%$ of referred case that may be the reason for slight low efficacy as compare to other studies. In this study, (36\%) patients underwent hysterectomy to control intractable, massive postpartum haemorrhage, it was nearly same in a study Kabadi YM et al (33.3\%). ${ }^{15}$ But uterus is conserved in (64\%) women in our study. Then main indication for obstetrical hysterectomy was adherent placenta (44\%), ruptured uterus (36\%) and atonic uterus (28\%). In (64\%) patients uterus is saved. It was comparable with study by Joshi $V$ et al $^{16}$ which reported $(60.7 \%)$, however some other studies showed higher percentage as reported by Yasmeen $\mathrm{N}$ et $\mathrm{al}^{17}$ (71.4\%). In all cases in which we tried to conserve uterus, uterine artery ligation and B-lynch suture were done before attempting to ligate bilateral internal iliac artery. This was also supported by Abha Singh et al. ${ }^{18}$

Out of 58 women with severe obstetric haemorrhage, $9(17 \%)$ were with post-operative internal haemorrhage and $8(13 \%)$ had coagulopathy. Torn vessels retracted within the pedicles so no definitive bleeding point was dectable, in such cases BIAL was the only answer. Out of total 17, 9 patients were saved by bilateral internal iliac artery ligation. This was also supported by Mukhopadhyay $\mathrm{P}$ et al. ${ }^{19}$ One of our patient needed re-laparotomy after BIAL. She had recurrent internal haemorrhage. Later on she expired due to DIC and multiorgan failure. One patient had injury to ureter, similarly such complication was reported by Mehmat et $\mathrm{al}^{20}$ one case of ureter ligation, while no such complication were noted in various other studies. ${ }^{13,20,21}$ BIAL as a procedure, with such a low complication rate and has very high rate of saving maternal life (90\%). Out of 58 women, 8 women (10\%) died unrelated to the procedure. These women died due to delayed referral and developed irreversible shock and multi-organ failure. Early referral, prompt management of $\mathrm{PPH}$, immediate availability of blood products and quick early decision of BIAL, not only save maternal life and also preserves fertility. All survived (50) patients discharged at (7-14 days) with few post-operative complications like fever, wound (5) infection and burst abdomen (2). Similar morbidity was also reported by Perveen et al and Mehmat et at. ${ }^{20,22}$ Due to some limitation, we have no long follow up system. Yildrim et al and Raba $G$ et al have claimed that BIAL has no unfavorable effect on ovarian function. ${ }^{22,23}$

\section{CONCLUSION}

In conclusion bilateral internal iliac artery ligation is effective and safe method to arrest and control massive obstetric maemorrhage (Such as postpartum haemorrhage and postoperative internal haemorrhage). Meticulous understanding of internal iliac artery and adjoing structures is mandatory to prevent intra-operative complications. Timely decision of BIAL not only save maternal life but also fertility. In my opinion all consultant obstetrician must be trained and should include in the algorithm to control massive obstetric haemorrhage.

\section{Copyright@C 18 May, 2020.}

\section{REFERENCES}

1. Department of Reproductive Health and research, world health organization WHO, UNICEF and UNFPA Estimation on Maternal Mortality in 2000. Geneva, Switzerland: World Health organization; 2004.

2. Jacob AJ, Lockwood CJ, Barss VA. Causes of treatment of postpartum haemorrhage. Up to date 2008; 16:1-3.

3. Condous GS, Arulkumaran S. Medical and conservative surgical management of postpartum haemorrhage. $J$ Obstet Gynaecol Can 2003; 25:931-6.

4. Dahlke JD, Mendez_Figueroa $H$, Maggio $L$, et al. Prevention and management of postpartum haemorrhage: A comparison of 4 national guidelines. Am J Obstet Gynecol 2015; 213:76.e1-10.

5. ACOG practice bulletin October 2006. Postpartum haemorrhage. Obstet Gynecol 2006; 108:1039-46. 
6. Say L, Chou D, Gemmill A, et al. Global care of maternal death: A WHO systemic analysis. Lancet Global health 2014; 2(6): e323-333.

7. Burkchell Re. Physiology of internal iliac artery ligation. J Obstet Gynecol for common w. 1968; 75(6):642-51

8. Papp Z, Sziller I, Hupuczi P. Controlling of profuse pelvic haemorrhage in Obstetrics and Gynaecology by hypogastric artery ligation. Current progress in Obstetrics and Gynaecology 2012; vol (1):198-214.

9. Camuzcuoglu H, Toy $\mathrm{H}$, Vural M, Yildiz F, Audin H. Internal iliac artery ligation for severe postpartum hemorrhage and severe hemorrhage after postpartum hysterectomy J Obstet Gynaecol Res 2010;36:538-43.

10. Kwawukaume EY, Ghosh TS. Extra peritoneal hypogastric artery ligation in control of intractable haemorrhage from advanced from carcinoma of cervix and choriocarcinoma. East Afr Med j 1996; 73:147-8.

11. Hunt BJ, Allard S, Kneeling D, et al; British committee for standards in Haematology. A practical guideline for the haemotological management of major haemorrhage. Br J Haematol 2015; 170:788-803.

12. Simsesk Y, Yilmaz E, Celik E, Abdullah TI, Turhan U, Celik $O$. Efficacy of internal iliac artery ligation on management of postpartum haemorrhage and its impact on the ovarian reserve. J Turk Soc Obstet Gynecol. 2012; 9(3):153-8.

13. Patil Y, Kathiriya D, Kshirsagar NS et al. Role of internal iliac artery ligation in control of pelvic haemorhage. Int. J Recent Trends Sci technol. 2014; 9(3):461-4.
14. Naithi V, Solanki J, Bilateral internal iliac artery ligation - a boon for severe postpartum haemorrhage. J Evol Med Dent Sci. 2013: 2(9):4.

15. Kabadi YM et al. int J Repord Contracept Obstet Gynecol. 2015 Oct; 4(5):1364-1366.

16. Joshi VM, Otiv SR, Majumder R, Nikam Y, Shrivastava M. Internal iliac artery ligation for arresting postpartum haemorrhage. BJOG 2007; 114:356-361.

17. Yasmeen N, Ahmad S, Latif F et al. Emergency bilateral internal artery ligation in control of post partum haemorrhage. APMC 2019; 13(1):64-8.

18. Singh A, Kishore R, Saxena SS. Ligating internal artery: Success beyond hesitation. The Journal of Obstetrics and Gynaecology of India (2012) 66(SI):S235-S241.

19. Mukhopadhyay P, Naskar T, Hazra S, et al. Emergency internal iliac artery ligation still a life saving procedure. J Obstet Gynecol Insdia. 2005; 55(2):144-5.

20. Evsen MS et al. Int Iliac Artery ligation for sever postpartum haemorrhage. Ginekol Pol 2012; 83:665-8.

21. Perveen F, Memon GU, Rabia S. Use of bilateral internal iliac artery ligation for controlling severe obstetric haemorrhage. Pakistan Journal of Medical Sciences. 2011 Jan 1;27(1).

22. Yildirim Y, Gultekin EKocyigit A, et al. Color Doppler analysis of pelvic arteries follow bilateral internal iliac artery ligation for severe postpartum Haemorrhage. int J Gynecol Obstet 2009; 104(1):22-4.

23. Raba G, Unilateral recanalization of hypogestine artery after ligation for post-partum haemorrhage treatment. Videosurgery Mini inv. 2014; 9(2)289-91.

\begin{tabular}{|c|c|c|c|}
\hline \multicolumn{4}{|c|}{ AUTHORSHIP AND CONTRIBUTION DECLARATION } \\
\hline Sr. \# & Author(s) Full Name & Contribution to the paper & Author(s) Signature \\
\hline 1 & $\begin{array}{l}\text { Saadia Saleem } \\
\text { Tasnim Tahira }\end{array}$ & $\begin{array}{l}\text { Manuscript designing, data } \\
\text { collection, analysis of results } \\
\text { and discussion writing. } \\
\text { Proof reading. }\end{array}$ & \\
\hline 3 & Naureen Javed & Review of literature & \\
\hline 4 & Sumera Tahir & Final layout. & \\
\hline
\end{tabular}

